\title{
Biological Activity of Matricaria Chamomilla Essential Oils of Various Chemotypes
}

\section{(우(1) $(8) \odot$}

\author{
Authors \\ Martina Höferl ${ }^{\mathbb{D}}$, Jürgen Wanner ${ }^{2}$, Nurhayat Tabanca ${ }^{3}$, Abbas Ali ${ }^{4}$, Velizar Gochev ${ }^{5}$, Erich Schmidt ${ }^{1}$, Vijay K. Kaul ${ }^{6}$, \\ Virendra Singh ${ }^{6}$, Leopold Jirovetz ${ }^{1}$
}

\section{Affiliations}

1 Department of Pharmaceutical Chemistry, University of Vienna, Vienna, Austria

2 Kurt Kitzing Co., Wallerstein, Germany

3 USDA-ARS, Subtropical Horticulture Research Station, Miami, USA

4 National Center for Natural Products Research, University of Mississippi, University, MS, USA

5 Department of Biochemistry and Microbiology, "Paisii Hilendarski”-University of Plovdiv, Plovdiv, Bulgaria

6 CSIR - Institute of Himalayan Bioresource Technology, Palampur, Himachal Pradesh, India

Key words

Matricaria chamomilla, Asteraceae, essential oil, chemotypes, Antimicrobial Molecular Targets and Activities, Aedes

$\begin{array}{ll}\text { received } & 16.12 .2019 \\ \text { revised } & 15.05 .2020 \\ \text { accepted } & 18.05 .2020\end{array}$

Bibliography

DOI https://doi.org/10.1055/a-1186-2400

Planta Med Int Open 2020; 7: e114-e121

(c) Georg Thieme Verlag KG Stuttgart · New York

ISSN 2509-9264

\section{Correspondence}

Dr. Martina Höferl

Department of Pharmaceutical Chemistry

University of Vienna, UZA-2

Althanstrasse 14

1090 Vienna

Austria

Tel.: + 4314277 55555, Fax: + 4314277855555

martina.hoeferl@univie.ac.at

\begin{abstract}
The essential oil of Matricaria chamomilla L., which is commonly used for medicinal and cosmetic purposes, can be differentiated between several chemotypes. In the current study, six essential chamomile oil samples of various origins (four of commercial sources, one of cultivation, one of wild collection) were examined regarding their composition and biological activities, i. e., antibacterial, antifungal, mosquito repellent, and larvicidal effects. GC-MS analyses revealed that the samples largely varied in composition and could be attributed to various chemotypes. In contrast to the other two samples, the four commercial samples were unusually high in trans- $\beta$-farnesene. The overall antimicrobial effects were only moderate, but it could be shown that a higher content in $\alpha$-bisabolol and a smaller in $\alpha$-bisabolol oxides A and B had a positive effect on overall activity. All samples had a biting deterrent effect comparable to DEET. Higher concentrations of $(Z)$ - and $(E)$-spiroethers improved larvicidal activity, whereas trans- $\beta$-farnesene had the opposite effect. In conclusion, the importance of $\alpha$ bisabolol for the biological activity of chamomile essential oil could be demonstrated.
\end{abstract}

\section{Introduction}

German chamomile [Matricaria chamomilla L., syn. Matricaria recutita L., Chamomilla recutita (L.) Rauschert, Asteraceae] is among the most valued medicinal plants worldwide. The dried flower heads as well as the essential oil are used as a medicinal drug (Matricariae flos and Matricariae aetheroleum[1] against a broad spectrum of symptoms in the form of tisanes, baths, inhalations, and mouthwashes [2]. Therapeutic indications include inflammatory condi- 
tions, bacterial infections, and lesions of the skin and mucosa (e.g., oral cavity, gastrointestinal tract, and respiratory tract), spasms, and ulcers of the gastrointestinal tract as well as insomnia and nervous disposition [2].

Phytochemical analyses have revealed that besides flavonoids (e. g., apigenin, luteolin) and their glycosides as well as coumarins (e. g., herniarin, umbelliferone), the essential oil can be considered crucial for the biological activities of chamomile flowers [3]. The essential oil is notably used in pharmaceutical and cosmetic preparations for its antibacterial [4], antifungal [5], antioxidant [6], and anti-inflammatory $[7,8]$ properties. The essential oil is mainly comprised of oxygenated sesquiterpenes of the bisabolane type. The blue colour typical for the majority of chamomile oil samples originates from chamazulene, an artefact of the distillation process derived from the nonvolatile sesquiterpene lactone matricin [7].

Within the species $M$. chamomilla, a chemical polymorphism regarding essential oil composition was first shown by Schilcher [9] and has been substantiated by several studies [10-14].

In the present study, the compositions of four commercial chamomile essential oil samples as well as a cultivated one and one sample of wild-growing populations were analysed regarding their composition, and antibacterial and anticandidal effects. Moreover, samples from Serbia, Hungary, South Africa, and India were evaluated against biting deterrent and larvicidal activities against Aedes aegypti L. Up to now, the influence of chemotype on biological activities of chamomile essential oils has not been evaluated thoroughly, which was another aim of our study.

\section{Results}

In the present study, the chemical compositions of four commercial essential oil samples, a sample of cultivated plants as well as a sample of collected wild plants were elucidated by means of simultaneous GC-FID and GC-MS. - Table 1 presents the results of the GC-FID and GC-MS analyses. In total, 114 compounds could be identified, amounting to $84.5-95.5 \%$. All samples had a low content in monoterpenes ( $>3 \%$ ) except for sample D from India ( $11.9 \%$, with $>2 \% \beta$-pinene and linalool) and sample $F(6.6 \%)$ but were dominated by sesquiterpenes (50-84\%). While samples A, C, and D were mainly composed of sesquiterpene hydrocarbons, no-

- Table 1 Chemical composition determined by simultaneous GC-FID and GC-MS of six essential oil samples of M. chamomilla L. of various origins.

\begin{tabular}{|c|c|c|c|c|c|c|c|}
\hline \multirow[t]{2}{*}{ Compound } & \multirow[t]{2}{*}{ RI\# } & \multicolumn{6}{|c|}{ Sample/provenance } \\
\hline & & A/Hungary & B/South Africa & C/Serbia & D/India & E/Hungary & F/India \\
\hline hexanal & 800 & - & - & - & - & $\operatorname{tr}$ & - \\
\hline ethyl 2-methyl butanoate & 848 & 0.1 & 0.1 & - & - & 0.1 & 0.3 \\
\hline ethyl isovalerate & 851 & - & - & - & - & $\operatorname{tr}$ & \\
\hline (Z)-3-hexenol & 852 & $\operatorname{tr}$ & - & - & - & - & 0.1 \\
\hline hexanol & 862 & - & - & - & - & - & $\operatorname{tr}$ \\
\hline tricyclene & 930 & - & - & - & 0.3 & - & - \\
\hline$\alpha$-pinene & 941 & $\mathrm{tr}$ & - & $\operatorname{tr}$ & 1.2 & - & 0.1 \\
\hline isopropyl 2-methylbutanoate & 943 & $\operatorname{tr}$ & $\operatorname{tr}$ & $\operatorname{tr}$ & - & 0.1 & 0.2 \\
\hline 3-buten-2-one & 948 & - & - & - & - & 0.5 & - \\
\hline camphene & 957 & - & - & - & 1.5 & - & $\operatorname{tr}$ \\
\hline isoamyl propanoate & 964 & - & - & - & - & - & 0.1 \\
\hline sabinene & 980 & - & - & 0.1 & - & $\operatorname{tr}$ & 0.5 \\
\hline 6-methyl-5-hepten-2-one & 984 & $\mathrm{tr}$ & 0.1 & $\mathrm{tr}$ & tr & 0.1 & 0.5 \\
\hline$\beta$-pinene & 985 & $\mathrm{tr}$ & - & - & 2.3 & - & - \\
\hline 6-methyl-5-hepten-2-ol & 989 & - & - & - & - & - & $\mathrm{tr}$ \\
\hline myrcene & 991 & - & - & $\operatorname{tr}$ & 0.1 & - & 0.1 \\
\hline 2-pentylfuran & 994 & 0.1 & 0.1 & - & - & $\operatorname{tr}$ & - \\
\hline yomogi alcohol & 997 & $\operatorname{tr}$ & 0.1 & 0.1 & - & 0.4 & 0.4 \\
\hline octanal & 1001 & 0.1 & 0.1 & - & $\mathrm{tr}$ & 0.1 & 0.1 \\
\hline (Z)-3-hexenyl acetate & 1003 & - & - & - & - & - & $\operatorname{tr}$ \\
\hline$\delta$-3-carene & 1017 & $\mathrm{tr}$ & - & - & - & - & - \\
\hline$\alpha$-terpinene & 1023 & - & - & - & - & $\operatorname{tr}$ & $\mathrm{tr}$ \\
\hline p-cymene & 1031 & 0.1 & 0.1 & 0.2 & 1.6 & 0.1 & 0.2 \\
\hline limonene & 1035 & 0.1 & 0.1 & $\operatorname{tr}$ & 0.1 & $\operatorname{tr}$ & 0.1 \\
\hline (Z)- $\beta$-ocimene & 1036 & 0.1 & $\operatorname{tr}$ & 0.1 & - & 0.1 & 0.1 \\
\hline 1,8-cineole & 1038 & - & 0.1 & - & 1.0 & 0.3 & 0.3 \\
\hline$(E)$ - $\beta$-ocimene & 1050 & 0.6 & 0.2 & 0.6 & 0.2 & 0.3 & 0.9 \\
\hline (E)-2-octenal & 1055 & - & - & - & - & $\operatorname{tr}$ & - \\
\hline 3-methyl-2-cyclohexen-1-one & 1055 & - & - & - & - & $\operatorname{tr}$ & - \\
\hline
\end{tabular}


Table 1 Continued

\begin{tabular}{|c|c|c|c|c|c|c|c|}
\hline \multirow[t]{2}{*}{ Compound } & \multirow[t]{2}{*}{ RI\# } & \multicolumn{6}{|c|}{ Sample/provenance } \\
\hline & & A/Hungary & B/South Africa & C/Serbia & D/India & E/Hungary & F/India \\
\hline artemisia ketone & 1062 & 0.3 & 0.4 & 0.6 & 0.1 & 0.5 & 2.0 \\
\hline$y$-terpinene & 1065 & 0.1 & $\operatorname{tr}$ & 0.2 & $\operatorname{tr}$ & 0.2 & 0.9 \\
\hline 1-nonen-3-ol & 1067 & - & - & - & - & tr & - \\
\hline octanol & 1068 & - & 0.1 & - & - & tr & 0.1 \\
\hline (Z)-sabinene hydrate & 1072 & - & $\operatorname{tr}$ & - & - & - & $\operatorname{tr}$ \\
\hline (Z)-linalool oxide & 1076 & - & - & - & $\operatorname{tr}$ & - & - \\
\hline artemisia alcohol & 1086 & 0.1 & 0.1 & 0.1 & - & 0.5 & 0.6 \\
\hline (E)-linalool oxide & 1092 & - & - & - & $\operatorname{tr}$ & - & \\
\hline (Z)-3-hexenyl propanoate & 1098 & - & - & - & - & tr & 0,1 \\
\hline isoamyl 2-methylbutyrate & 1101 & - & - & - & - & - & 0.1 \\
\hline linalool & 1102 & - & - & - & 2.2 & 0.1 & 0.1 \\
\hline nonanal & 1102 & 0.1 & 0.1 & - & - & tr & - \\
\hline acetate of yomogi alcohol & 1111 & - & - & - & - & tr & - \\
\hline hexyl isobutanoate & 1146 & - & - & - & - & tr & - \\
\hline (E)-pinocarveol & 1150 & - & - & - & 0.1 & - & - \\
\hline 4-acetyl-1-methyl-cyclohexene & 1155 & - & - & - & - & tr & - \\
\hline camphor & 1154 & - & - & - & - & - & 0.3 \\
\hline (E)-chrysanthemol & 1160 & - & - & - & - & 0.1 & 0.1 \\
\hline (E)-2-nonenal & 1165 & - & - & - & - & - & 0.2 \\
\hline lavandulol & 1167 & - & - & - & - & - & 0.2 \\
\hline isoborneol & 1167 & - & - & - & - & 0.1 & - \\
\hline artemisyl acetate & 1169 & $\operatorname{tr}$ & 0.2 & - & - & 0.2 & - \\
\hline borneol & 1177 & - & - & - & - & 0.1 & 0.2 \\
\hline terpinen-4-ol & 1186 & - & - & - & - & 0.1 & 0.3 \\
\hline hexyl butanoate & 1189 & - & - & - & - & $\mathrm{tr}$ & - \\
\hline$\alpha$-terpineol & 1198 & - & - & $\mathrm{tr}$ & 1.8 & 0.2 & 0.2 \\
\hline decanal & 1204 & - & - & - & - & tr & - \\
\hline$\gamma$-terpineol & 1204 & - & - & - & 0.3 & - & - \\
\hline 4,8-dimethyl-7-nonen-2-one & 1227 & - & - & - & - & 0.1 & - \\
\hline (Z)-3-hexenyl-2-methylbutanoate & 1231 & - & - & - & - & $\operatorname{tr}$ & $\operatorname{tr}$ \\
\hline (Z)-3-hexenyl-3-methylbutanoate & 1234 & - & - & - & - & 0.1 & 0.1 \\
\hline $\begin{array}{l}\text { 4,8-dimethyl-3,7-nonadien-2-one } \\
\text { isomer } 1\end{array}$ & 1238 & - & - & - & - & 0.3 & - \\
\hline benzyl propanoate & 1258 & - & - & - & - & - & 0.1 \\
\hline geranial & 1274 & - & - & - & 0.1 & - & - \\
\hline $\begin{array}{l}\text { 4,8-dimethyl-3,7-nonadien-2-one } \\
\text { isomer } 2\end{array}$ & 1275 & - & 0.4 & - & - & 1.2 & - \\
\hline methyl geranate & 1275 & 0.1 & - & 0.3 & - & - & 0.3 \\
\hline lavandulyl acetate & 1288 & - & - & - & - & tr & - \\
\hline$(E, E)$-2,4-decadienal & 1319 & - & - & - & - & tr & - \\
\hline$\delta$-elemene & 1352 & - & - & 0.2 & - & - & - \\
\hline$\alpha$-copaene & 1359 & - & - & 0.1 & - & - & - \\
\hline caprinic acid & 1360 & 0.3 & 0.4 & 0.1 & 0.6 & 0.5 & - \\
\hline benzyl isovalerate & 1398 & - & - & - & - & - & 0.1 \\
\hline tetradecane & 1399 & - & 0.1 & - & - & - & - \\
\hline$\beta$-elemene & 1406 & 0.2 & 0.1 & 0.2 & 0.2 & 0.1 & 0.2 \\
\hline$\alpha$-isocomene & 1411 & 0.2 & 0.3 & 0.4 & 0.3 & - & - \\
\hline 2,5-dimethoxy-p-cymene & 1423 & - & 0.3 & - & - & - & - \\
\hline$(Z)$ - $\beta$-farnesene & 1434 & - & - & - & 0.7 & - & - \\
\hline$(E)$ - $\beta$-caryophyllene & 1442 & 0.2 & 0.2 & 0.3 & 0.4 & 0.1 & 0.1 \\
\hline
\end{tabular}


- Table 1 Continued

\begin{tabular}{|c|c|c|c|c|c|c|c|}
\hline \multirow[t]{2}{*}{ Compound } & \multirow[t]{2}{*}{ RI\# } & \multicolumn{6}{|c|}{ Sample/provenance } \\
\hline & & A/Hungary & B/South Africa & C/Serbia & D/India & E/Hungary & F/India \\
\hline$(E)$ - $\alpha$-bergamotene & 1448 & - & 0.3 & - & - & - & - \\
\hline geranyl acetone & 1453 & - & 0.2 & - & - & - & - \\
\hline$(E)$ - $\beta$-farnesene & 1460 & 38.5 & 18.7 & 38.4 & 24.1 & 3.3 & 7.2 \\
\hline (Z,Z)- $\alpha$-farnesene & 1475 & - & - & - & 1.0 & - & - \\
\hline dihydrosesquicineole & 1479 & 0.2 & 0.2 & 0.3 & 0.6 & 0.4 & 1.4 \\
\hline allo-aromadendrene & 1486 & 0.1 & 0.2 & 0.1 & - & - & - \\
\hline$\gamma$-curcumene & 1490 & 0.1 & 0.8 & - & - & 0.1 & - \\
\hline$(Z, E)$ - $\alpha$-farnesene & 1497 & - & - & 0.6 & 0.6 & - & - \\
\hline$(E, Z)$ - $\alpha$-farnesene & 1496 & 0.6 & 0.4 & - & 0.9 & - & - \\
\hline pentadecane & 1499 & 0.1 & 0.2 & - & - & - & - \\
\hline germacrene D & 1503 & 2.3 & 1.4 & 3.1 & 1.0 & 0.5 & 1.6 \\
\hline$(E, E)$ - $\alpha$-farnesene & 1510 & 5.8 & 1.3 & 5.6 & 4.5 & 0.2 & 0.8 \\
\hline bicyclogermacrene & 1518 & 1.9 & 1.2 & 2.0 & - & 0.4 & 1.1 \\
\hline$\beta$-bisabolene & 1519 & - & - & - & 1.5 & - & - \\
\hline (Z)- $\gamma$-bisabolene & 1529 & - & - & - & 0.5 & - & - \\
\hline$\beta$-sesquiphellandrene & 1535 & - & 0.5 & - & - & - & - \\
\hline $\mathrm{Y}$-cadinene & 1537 & 0.2 & - & 0.1 & - & - & 0.1 \\
\hline$\delta$-cadinene & 1539 & 0.2 & 0.3 & 0.4 & 0.2 & $\operatorname{tr}$ & 0.1 \\
\hline trans- $\gamma$-bisabolene & 1544 & - & - & - & 0.3 & - & - \\
\hline isohumbertiol B & 1546 & - & - & - & - & 0.1 & - \\
\hline$(Z)$-nerolidol & 1551 & - & - & - & - & $\operatorname{tr}$ & - \\
\hline (E)- $\alpha$-bisabolene & 1552 & - & - & - & 2.7 & - & - \\
\hline (E)-nerolidol & 1568 & 0.2 & 1.4 & 0.4 & 0.2 & 0.8 & 0.2 \\
\hline (E)-dendrolasin & 1580 & 0.2 & 0.5 & 0.1 & 0.2 & 0.1 & - \\
\hline spathulenol & 1602 & 0.7 & 5.7 & 0.6 & 0.7 & 0.8 & - \\
\hline caryophyllene oxide & 1610 & - & - & - & - & 0.1 & - \\
\hline T-cadinol & 1661 & 0.4 & 0.8 & 0.3 & 0.2 & 0.2 & 0.5 \\
\hline$\alpha$-bisabolol oxide B & 1676 & 3.9 & 12.1 & 5.8 & 5.9 & 3.1 & 17.0 \\
\hline$\alpha$-bisabolol & 1703 & 1.2 & 1.9 & 11.5 & 5.7 & 38.3 & 6.2 \\
\hline$(E, E)$-farnesol & 1704 & - & - & - & 5.6 & - & - \\
\hline epi- $\alpha$-bisabolol & 1705 & - & - & - & - & 0.5 & - \\
\hline$\alpha$-bisabolone oxide A & 1707 & 3.0 & 8.5 & 2.8 & 5.2 & 0.1 & 7.3 \\
\hline$(E, Z)$-farnesol & 1728 & - & - & - & 4.0 & - & - \\
\hline chamazulene & 1763 & 1.3 & 4.4 & 8.0 & 0.6 & 21.6 & 6.8 \\
\hline$\alpha$-bisabolol oxide A & 1770 & 24.1 & 6.9 & 6.3 & 6.0 & 1.0 & 25.0 \\
\hline guajazulene & 1808 & - & - & - & - & 0.2 & - \\
\hline phytol & 1848 & 0.3 & 1.1 & 0.3 & 0.5 & - & - \\
\hline (Z)-spiroether & 1887 & 5.5 & 10.4 & 1.3 & 2.6 & 0.1 & 6.0 \\
\hline (E)-spiroether & 1900 & 0.6 & 1.6 & 0.2 & 0.3 & 16.8 & 0.6 \\
\hline palmitic acid & 1954 & - & - & - & - & 0.3 & - \\
\hline Sum & & 94.2 & 84.5 & 91.7 & 90.9 & 95.5 & 92.2 \\
\hline
\end{tabular}

tably ( $E$ )- $\beta$-farnesene, oxygenated sesquiterpenes prevailed in samples $\mathrm{B}$ and $\mathrm{F}$ ( $\alpha$-bisabolol oxides $\mathrm{A}$ and $\mathrm{B}, \alpha$-bisabolone oxide $\mathrm{A}$ ) as well as sample $\mathrm{E}$ (main compound $\alpha$-bisabolol). The latter had also notably high concentrations of azulenes $(21.8 \%)$ and spiroethers (16.9\%), not only compared to the other samples ( $<10 \%$ ) but also other samples from Hungary [15]. As both $\alpha$-bisabolol $[8,16]$ and chamazulene [17-19] proved to possess anti-inflammatory and highly antioxidant properties $[14,17,20]$, this combination is highly preferable for pharmaceutical and cosmetic use.

All of the commercially available samples were found to have a remarkably high content of trans- $\beta$-farnesene (18.7-38.5\%) compared to sample $E$ from the wild collection in Hungary (3.3\%) and sample F from North India (7.2\%). Among the reasons for these unusually high levels, the developmental stage of the harvested 
plants as well as the use of vegetative plant parts [21] can be discussed. These results are supported by a study by Su et al. who showed that the activity of ( $E$ )- $\beta$-farnesene synthase, and thus $(E)$ - $\beta$-farnesene production, is influenced by the plant part investigated (highest in leaves, lowest in disc flowers) and the developmental stage of the plant (highest in semi-opened flowers, lowest in fully opened flowers) amongst other factors like distillation time [22].

In $>$ Table 2, the results of the antimicrobial activity screening are given. As demonstrated before, chamomile essential oil exerts antibacterial effects $[4,20]$, particularly against gram-positive bacteria like Staphylococcus aureus as well as anticandidal activity [14] against Candida albicans. However, gram-negative bacteria, especially Pseudomonas aeruginosa, were less susceptible. In this respect, this result was predictable as $P$. aeruginosa is protected against terpenoids and other chemicals by its outer membrane and specific efflux mechanisms [23]. Compared to other essential oils, the overall antimicrobial activity was mediocre, but our findings go along with those of Satyal et al. [14]. While our findings corroborate previous findings concerning the antibacterial effects of pure $\alpha$-bisabolol [24], there is also evidence for a negative effect of $\alpha$-bisabolol oxides A and B on antimicrobial activity as shown by samples $A$ and $F$.

The in vitro K\&D system used in this study specifically quantified the mosquito biting deterrent properties of five essential oils of $M$. chamomilla. Biting deterrent indices (BDI) of the essential oils against Aedes aegypti are given in > Fig. 1. All the essential oil samples showed biting deterrent activity above the negative control ethanol, and the activity of all samples was similar to DEET at 25 $\mathrm{nmol} / \mathrm{cm}^{2}$. A high content in $\alpha$-bisabolol as well as monoterpenes might have a positive influence on biting deterrence, but the differences were minimal.

Data on the toxicity against the larvae of $A$. aegypti is presented in $>$ Table 3. The toxicity of sample $B$ (South Africa) with an $L_{50}$ of $2.9 \mathrm{ppm}$ was significantly higher than all the other samples, followed by sample $F$ (India) with an $\mathrm{LD}_{50}$ of 8.2 ppm. Samples $A$ (Hungary), C (Serbia), and D (India) exhibited similar mortalities with $\mathrm{LD}_{50}$ values of $60.5,49.3$, and $45.4 \mathrm{ppm}$, respectively. Sample E was not included in these assays. The high toxicity of samples $B$ and $F$ might be explained by its relatively high content in spiroethers (12.0 and 6.6\%, respectively). Polyines (or polyacetylenes), especially those found in the genus Artemisia, have been known to possess high larvicidal activity for a long time [25]. In contrast, higher yields of sesquiterpene hydrocarbons, especially $(E)$ - $\beta$-farnesene, had a negative effect on toxicity in Aedes larvae in this study.

\section{Discussion}

Since 1973 [9], the chemical polymorphism of German chamomile regarding its essential oil has been established. Originally, Schilcher [10] proposed four chemotypes based on varying contents in sesquiterpene compounds: Type A, mainly found in Central, South, and East Europe, is dominated by bisabolol oxide B, Type B (South America) by bisabolol oxide A, and Type C by $\alpha$-bisabolol, while Type $D$ is composed of comparable quantities of these three sesquiterpenes. Additionally, a variant low in matricin (prochamazulene) was mentioned. This classification has been used by many authors $[13,15,26,27]$, however, Type $A$ and $B$ have been interchanged. Later, Horn et al. [28] could identify four chemotypes as follows: Type I dominated by $\alpha$-bisabolol and matricin, Type lla by $\alpha$-bisabolol oxide A and matricin, Type Ilb by $\alpha$-bisabolol oxide B and matricin, and Type III high in $\alpha$-bisabolone oxide but devoid of $\alpha$-bisabolol and matricin. Horn et al. [28] as well as Massoud and Franz $[29,30]$ also elucidated the genetically controlled mechanisms for the formation of $\alpha$-bisabolol and its derivatives as well as

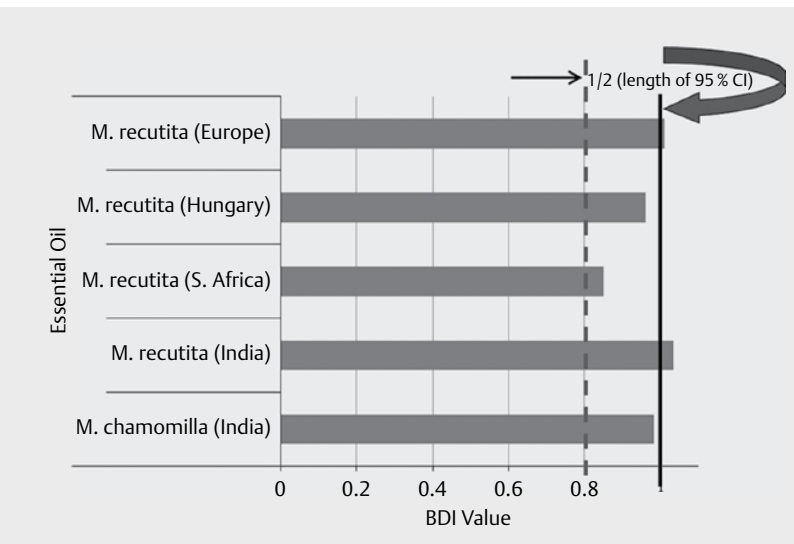

- Fig. 1 Biting deterrent indices (BDI) of five essential oils $(10 \mu \mathrm{g} /$ $\mathrm{cm}^{2}$ ) of Matricaria chamomilla $\mathrm{L}$. from various parts of the world against female $A$. aegypti. Ethanol was the solvent control and DEET at $25 \mathrm{nmol} / \mathrm{cm}^{2}$ was used as positive control. Mean BDI falling between $1 / 2$ length of $95 \% \mathrm{Cl}$ and 1 are statistically similar to DEET.

- Table 2 Minimal bactericidal/fungicidal concentrations $(\mu \mathrm{g} / \mathrm{mL})$ of six essential oils of $M$. chamomilla L. of various origins.

\begin{tabular}{|c|c|c|c|c|c|c|c|c|c|c|c|}
\hline \multirow[t]{2}{*}{ Test strain } & \multicolumn{6}{|c|}{ Essential oils } & \multicolumn{5}{|c|}{ Controls } \\
\hline & A & B & C & D & $\mathbf{E}$ & $\mathbf{F}$ & Ac & $\mathrm{Ci}$ & $\mathrm{Ce}$ & $\mathrm{Na}$ & Va \\
\hline S. aureus ATCC 6538 & 4000 & 2000 & 2000 & 4000 & 2000 & 8000 & 0.5 & 0.125 & 0.125 & 0.063 & 0.5 \\
\hline E. coli ATCC 25922 & 4000 & 2000 & 4000 & 2000 & 2000 & 8000 & 0.5 & 0.25 & 0.25 & 0.125 & 0.25 \\
\hline S. abony ATCC 6017 & 4000 & 2000 & 4000 & 2000 & 2000 & 8000 & 0.5 & 0.5 & 0.5 & 0.5 & 0.5 \\
\hline \multirow[t]{2}{*}{ P. aeruginosa ATCC 9027} & 4000 & 4000 & 8000 & 4000 & 4000 & 8000 & 32 & 1.0 & 2.0 & 4.0 & 8.0 \\
\hline & & & & & & & Am & $\mathrm{Fl}$ & It & Ke & Vo \\
\hline C. albicans ATCC 10231 & 2000 & 2000 & 2000 & 2000 & 2000 & 4000 & 0.25 & 0.25 & 0.25 & 0.023 & 0.016 \\
\hline
\end{tabular}

$\mathrm{Ac}=$ amoxicillin, $\mathrm{Ci}=$ ciprofloxacin, $\mathrm{Ce}=$ cefazolin, $\mathrm{Na}=$ nalidixic acid, $\mathrm{Va}=$ vancomycin; $\mathrm{Am}=$ amphotericin $\mathrm{B}, \mathrm{Fl}=\mathrm{fluconazole}, \mathrm{It}=$ itraconazole, $\mathrm{Ke}=$ ketoconazole, Vo= voriconazole. 
> Table 3 Toxicity of essential oils of M. chamomilla from various parts of the world against 1-day-old larvae of A. aegypti $24 \mathrm{~h}$ post-treatment.

\begin{tabular}{|c|c|c|c|c|}
\hline \multirow[t]{2}{*}{ Essential oil } & \multicolumn{4}{|c|}{ Aedes aegypti } \\
\hline & $\mathrm{LC}_{50}(95 \% \mathrm{Cl})^{*}$ & $\mathrm{LC}_{90}(95 \% \mathrm{Cl})$ & $\mathrm{x}^{2}$ & DF \\
\hline Sample A (Hungary) & $60.5(54.2-67.8)$ & $99.9(86.3-124.4)$ & 59.8 & 48 \\
\hline Sample B (S. Africa) & $2.9(2.6-3.2)$ & $4.4(3.9-5.2)$ & 54.6 & 48 \\
\hline Sample C (Serbia) & $49.3(43.2-56.6)$ & $103.4(85.7-135.3)$ & 79.3 & 48 \\
\hline Sample D (India) & $45.4(40.3-51.1)$ & $81.7(69.9-102.5)$ & 67.6 & 48 \\
\hline Sample F (India) & $8.2(7.4-9.0)$ & $12.6(11.3-15.6)$ & 52.2 & 48 \\
\hline Permethrin $^{* *}$ & $0.0034(0.003-0.0038)$ & & & \\
\hline
\end{tabular}

chamazulene and identified the responsible genes, thus assigning genotypes to the chemotypes. As some of these chemotypes form locally distinct populations, they could also be termed "chemodem" [31]; however, this term is rarely used in literature. Moreover, some authors suggested spiroether $[14,32]$ and trans- $\beta$ farnesene [14] chemotypes; however, Satyal et al. [14] analysed the essential oil of the aerial parts. Interestingly, the European Pharmacopoeia differentiates between only two chemotypes, one rich in $\alpha$-bisabolol (10-65\%) and one dominated by bisabolol oxides (29-81\%) [1].

Considering that a high trans- $\beta$-farnesene level might also be ascribed to a premature harvesting or use of stems and leaves, the samples in the current study could be characterised as follows: Sample A (Hungary) is a representative of the $\alpha$-bisabolol oxide A/ matricin type, and sample $\mathrm{E}$ (Hungary) is typical for the $\alpha$-bisabolol/ matricin type, both of which are commonly found in Hungary [15]. Sample F (North India) can also be attributed to the $\alpha$-bisabolol oxide $\mathrm{A} /$ matricin type (though also rich in $\alpha$-bisabolol oxide $\mathrm{B}$ ), which is apparently common for this region [33] as well as the Ganges plains [34]. Sample B (South Africa) might represent the $\alpha$ bisabolol oxide B/matricin type, whereas sample C (Serbia) could be an example of Schilcher's Type $D$, which is prevalent in this geographical region $[35,36]$. Sample D (India) might also be attributed to Type $\mathrm{D}$, even though it is also rich in $\alpha$-bisabolone oxide and poor in chamazulene. However, the limited data on used cultivars, harvesting, and essential oil production of the commercial samples should be pointed out.

In conclusion, our study could demonstrate that the quantitative differences regarding the chemical composition of $\mathrm{M}$. chamomilla essential oils crucially influence biological activities such as antimicrobial, insect repellent, and larvicidal effects. To our knowledge, this is the first published study that directly compared chamomile essential oils of different provenance and chemotype in this respect. Regarding essential oil composition, essential oils of chemotypes rich in $\alpha$-bisabolol, chamazulene, and spiroethers should be preferred over chemotypes dominated by trans- $\beta$-farnesene and $\alpha$-bisabolol oxides for use in pharmaceutical and cosmetic products as these compounds have been shown once more to have positive effects on various activities of chamomile essential oil.

\section{Materials and Methods}

\section{Plant material}

Three essential oil samples were purchased from Paul Kaders (Hamburg, Germany): sample A (Lot. nr. 122300/260810, Hungary), sample B (Lot. nr. 12302/260810, South Africa), and sample D (Lot. nr. 122306/260810, India). Sample C (Lot. nr. 38595, Serbia) was purchased from Unterweger (Thal-Assling, Austria). Sample E was prepared in 2009 by Beata Gosztola and authenticated by Prof. Eva Nemeth (Corvinus University, Budapest, Hungary) from plants of a wild-growing population of $M$. chamomilla. For sample $F$, the plants were cultivated and harvested by Dr. Virendra Singh at the CSIR-Institute of Himalayan Bioresource Technology (Palampur, India) from April to May 2014, and authenticated by V. K. Kaul. The aerial parts containing $95 \%$ flowers were distilled using a Clevenger-type apparatus; the oil yield was $0.1 \%$.

\section{Essential oil analysis}

GC-FID and GC-MS analyses as well as identification and quantification of the compounds were carried out as described earlier [37]. Retention indices [38] were compared to retention indices of reference compounds and from literature data [39-42] to confirm the peak data. Quantification of compounds was performed using normalised peak area calculations of the FID chromatogram.

\section{Microbiological assays}

The antimicrobial effects of the essential oils were tested against the following strains of microorganisms: S. aureus ATCC 6538, Escherichia coli ATCC 25922, Salmonella abony ATCC 6017, P. aeruginosa ATCC 9027, and C. albicans ATCC 10231, all obtained from culture collections of The National Bank of Industrial Microorganisms and Cell Cultures (NBIMCC, Bulgaria). Nutritional agar, Mueller-Hinton broth and agar as well as Sabouraud dextrose broth and agar were obtained from the National Center of Infectious and Parasitic Diseases (NCIPD, Bulgaria). For positive controls, HiComb MIC test strips were obtained from HiMedia Laboratories Ltd. Antibacterial and anticandidal susceptibility testing was carried out as described in detail previously [43].

\section{Mosquito bioassays}

Both the larvae and adult mosquitoes used in these studies were from the laboratory colonies maintained at the Mosquito and Fly Research Unit at the Center for Medical, Agricultural and Veterinary 
Entomology, USDA-ARS, Gainesville, Florida. Maintenance conditions and bioassays are described in detail elsewhere [44].

For biting bioassays, two sets of replications, consisting of six treatments (four test compounds, DEET at $25 \mathrm{nmol} / \mathrm{cm}^{2}$, and ethanol-treated organdy as a solvent control) each with five females per treatment, were conducted on two different days using a newly treated organdy and a new batch of females in each replication. Treatments were replicated nine times.

Regarding the larval bioassay, larvae that showed no movement in the well after manual disturbance of water were recorded as dead. A series of 5 concentrations ranging between 125 and 0.98 ppm were used in different treatments to obtain a range of mortality. Permethrin (46.1\% cis/53.2\% trans; Chemical Service) was used as a positive control. Treatments were replicated ten times for each of the treatments.

\section{Statistical analyses}

Proportion not biting (PNB) and biting deterrence index (BDI) were calculated as described before [44]. A BDI value of 0 indicates an effect similar to ethanol, while a value significantly greater than 0 indicates a biting deterrent effect relative to ethanol. BDI values that were not significantly different from 1 are statistically similar to DEET. BDI values were analysed using SAS Proc ANOVA [single factor: test compound (fixed)], (SAS Institute 2007), and means were separated using the Ryan-Einot-Gabriel-Welsch Multiple Range Test. To determine whether confidence intervals (Cls) include the values of 0 or 1 for treatments, Scheffe's multiple comparison procedure with the option of CLM was used in SAS. LC 50 values for larvicidal data were calculated by using SAS, Proc Probit. Control mortality was corrected by using Abbott's formula [45]. Toxicity was compared among treatments based on non-overlapping 95\% Cls [46].

\section{Conflict of Interest}

The authors declare thay they have no conflict of interest.

\section{References}

[1] Europäisches Arzneibuch (Ph.Eur. 8.8): Amtliche österreichische Ausgabe. 8. Ausgabe, 8. Nachtrag. Wien: Verlag Österreich; 2016

[2] Matricariae flos In: Wichtl M, Bauer R, editors Teedrogen und Phytopharmaka: ein Handbuch für die Praxis auf wissenschaftlicher Grundlage. Stuttgart. Wissenschaftliche Verlagsgesellschaft; 2009: $420-422$

[3] Singh O, Khanam Z, Misra N, Srivastava MK. Chamomile (Matricaria chamomilla L.): An overview. Pharmacogn Rev 2011; 5: 82-95

[4] Kazemi M. Chemical Composition and Antimicrobial Activity of Essential Oil of Matricaria recutita. Int J Food Prop 2015; 18: 1784-1792

[5] Tolouee M, Alinezhad S, Saberi R, Eslamifar A, Zad S], Jaimand K, Taeb J, Rezaee M-B, Kawachi M, Shams-Ghahfarokhi M, Razzaghi-Abyaneh M. Effect of Matricaria chamomilla L. flower essential oil on the growth and ultrastructure of Aspergillus niger van Tieghem. Int J Food Microbiol 2010; 139: 127-133
[6] Formisano C, Delfine S, Oliviero F, Tenore GC, Rigano D, Senatore F. Correlation among environmental factors, chemical composition and antioxidative properties of essential oil and extracts of chamomile (Matricaria chamomilla L.) collected in Molise (South-central Italy). Ind Crops Prod 2015; 63: 256-263

[7] Ramadan M, Goeters S, Watzer B, Krause E, Lohmann K, Bauer R, Hempel B, Imming P. Chamazulene carboxylic acid and matricin: A natural profen and its natural prodrug, identified through similarity to synthetic drug substances. J Nat Prod 2006; 69: 1041-1045

[8] Rocha NFM, Rios ERV, Carvalho AMR, Cerqueira GS, Lopes Ade A, LKAM Leal, Dias ML, de Sousa DP, de Sousa FCF. Anti-nociceptive and anti-inflammatory activities of ( -$)$ - $\alpha$-bisabolol in rodents. Naunyn Schmiedebergs Arch Pharmacol 2011; 384: 525-533

[9] Schilcher H. Neuere Erkenntnisse bei der Qualitätsbeurteilung von Kamillenblüten bzw. Kamillenöl. Planta Med 1973; 23: 132-144

[10] Schilcher H. Die Kamille: Handbuch für Ärzte, Apotheker und andere Naturwissenschaftler. Stuttgart: Wissenschaftliche Verlagsgesellschaft. 1987

[11] Franz C. Genetics. In: Hay RKM, Waterman PG, editors Volatile Oil Crops: Their Biology, Biochemistry and Production. Harlow: Longman Scientific \& Technical; 1993

[12] Wagner C, Friedt W, Marquard RA, Ordon F. Molecular analyses on the genetic diversity and inheritance of ( - )- $\alpha$-bisabolol and chamazulene content in tetraploid chamomile (Chamomilla recutita (L.) Rausch.). Plant Sci 2005; 169: 917-927

[13] Rubiolo P, Belliardo F, Cordero C, Liberto E, Sgorbini B, Bicchi C. Headspace-solid-phase microextraction fast GC in combination with principal component analysis as a tool to classify different chemotypes of chamomile flower-heads (Matricaria recutita L.). Phytochem Anal 2006; 17: 217-225

[14] Satyal P, Shrestha S, Setzer WN. Composition and bioactivities of an (E)- $\beta$-farnesene chemotype of chamomile (Matricaria chamomilla) essential oil from Nepal. Nat Prod Commun 2015; 10: 1453-1457

[15] Gosztola B, Németh E, Sárosi S, Szabó K, Kozák A. Comparative evaluation of chamomile (Matricaria recutita L.) populations from different origin. Int J Hortic Sci 2006; 12: 91-95

[16] Braga PC, Dal Sasso M, Fonti E, Culici M. Antioxidant activity of bisabolol: Inhibitory effects on chemiluminescence of human neutrophil bursts and cell-free systems. Pharmacology 2009; 83 : 110-115

[17] Capuzzo A, Occhipinti A, Maffei ME. Antioxidant and radical scavenging activities of chamazulene. Nat Prod Res 2014; 28: 2321-2323

[18] Safayhi H, Sabieraj J, Sailer ER, Ammon HP. Chamazulene: An antioxidant-type inhibitor of leukotriene B4 formation. Planta Med 1994; 60: 410-413

[19] Rekka EA, Kourounakis AP, Kourounakis PN. Investigation of the effect of chamazulene on lipid peroxidation and free radical processes. Res Commun Mol Pathol Pharmacol 1996; 92: 361-364

[20] Barbosa LN, da Silva Probst I, Teles Andrade BFM, Bérgamo Alves FC, Albano M, de Lourdes Ribeiro de Souza da Cunha M, Doyama JT, Mores Rall VL, Júnior AF. In vitro Antibacterial and chemical properties of essential oils including native plants from brazil against pathogenic and resistant bacteria. J Oleo Sci 2015; 64: 289-298

[21] Wesolowska A, Grzeszczuk M, Kulpa D. Propagation method and distillation apparatus type affect essential oil from different parts of Matricaria recutita L. plants. J Essent Oil Bear Plants 2015; 18: 179-194

[22] Su S, Liu X, Pan G, Hou X, Zhang H, Yuan Y. In vitro characterization of a (E)- $\beta$-farnesene synthase from Matricaria recutita $\mathrm{L}$. and its up-regulation by methyl jasmonate. Gene 2015; 571: 58-64

[23] Cox SD, Markham JL. Susceptibility and intrinsic tolerance of Pseudomonas aeruginosa to selected plant volatile compounds. J Appl Microbiol 2007; 103: 930-936 
[24] Forrer M, Kulik EM, Filippi A, Waltimo T. The antimicrobial activity of $\alpha$-bisabolol and tea tree oil against Solobacterium moorei, a Grampositive bacterium associated with halitosis. Arch Oral Biol 2013; 58: $10-16$

[25] Arnason T, Swain T, Wat CK, Graham EA, Partington S, Towers GHN, Lam J. Mosquito larvicidal activity of polyacetylenes from species in the Asteraceae. Biochem Syst Ecol 1981; 9: 63-68

[26] Gosztola B, Sarosi S, Nemeth E. Variability of the essential oil content and composition of chamomile (Matricaria recutita L.) affected by weather conditions. Nat Prod Commun 2010; 5: 465-470

[27] Salamon I. Chamomile biodiversity of the essential oil qualitativequantitative characteristics. In: Sener B, editor Innovations in Chemical Biology. Dordrecht: Springer Netherlands; 2009: 83-90

[28] Horn W, Franz C, Wickell I. Zur Genetik der Bisaboloide bei der Kamille. Plant Breed 1988; 101: 307-312

[29] Massoud H, Franz C. Quantitative genetical aspects of Chamomilla recutita (L.) Rauschert. J Essent Oil Res 1990; 2: 15-20

[30] Massoud HY, Franz CM. Quantitative genetical aspects of Chamomilla recutita (L.) Rauschert II. Genotype-environment interactions and proposed breeding methods. J Essent Oil Res 1990; 2: 299-305

[31] Hegnauer R. Phytochemistry and plant taxonomy-An essay on the chemotaxonomy of higher plants. Phytochemistry 1986; 25 : 1519-1535

[32] Taviani P, Rosellini D, Veronesi F. Variation for agronomic and essential oil traits among wild populations of Chamomilla recutita (L.) Rauschert from central Italy. J Herbs Spices Med Plants 2002; 9: 353-358

[33] Sashidhara KV, Verma RS, Ram P. Essential oil composition of Matricaria recutita $\mathrm{L}$. from the lower region of the Himalayas. Flavour Fragr J 2006; 21: 274-276

[34] Das M, Ram G, Singh A, Mallavarapu GR, Ramesh S, Ram M, Kumar S. Volatile constituents of different plant parts of Chamomilla recutita $\mathrm{L}$. Rausch grown in the Indo-Gangetic plains. Flavour Fragr J 2002; 17: 9-12

[35] Stanojevic LP, Marjanovic-Balaban ZR, Kalaba VD, Stanojevic JS, Cvetkovic DJ. Chemical composition, antioxidant and antimicrobial activity of chamomile flowers essential oil (Matricaria chamomilla L.). | Essent Oil Bear Plants 2016; 19: 2017-2028
[36] Acimovic M, Stankovic ], Cvetkovic M, Kiprovski B, Todosijevic M. Essential oil quality of tetraploid chamomile cultivars grown in Serbia. J Essent Oil Bear Plants 2018; 21: 15-22

[37] Stappen I, Wanner J, Tabanca N, Wedge DE, Ali A, Khan IA, Kaul VK, Lal B, Jaitak V, Gochev V, Girova T, Stoyanova A, Schmidt E, Jirovetz L. Chemical composition and biological effects of Artemisia maritima and Artemisia nilagirica essential oils from wild plants of Western Himalaya. Planta Med 2014; 80: 1079-1087

[38] van Den Dool H, Kratz PD. A generalization of the retention index system including linear temperature programmed gas-liquid partition chromatography. J Chromatogr A 1963; 11: 463-471

[39] Joulain D, König WA. The Atlas of Spectral Data of Sesquiterpene Hydrocarbons. Hamburg: EB Verlag; 2008

[40] Heller SR, Milne GWA. EPA/NIH Mass Spectral Data Base. Wash DC: US Gov Print Off; 1978

[41] Stenhagen E, Abrahamsson S, McLafferty FW. Registry of Mass Spectral Data. New York: Wiley; 1974

[42] Swigar AA, Siverstein RM. Monoterpenes. Milwaukee: Aldrich Chemical Co. 1981;

[43] Wanner J, Schmidt E, Bail S, Jirovetz L, Buchbauer G, Gochev V, Girova T, Atanasova T, Stoyanova A. Chemical composition, olfactory evaluation and antimicrobial activity of selected essential oils and absolutes from Morocco. Nat Prod Commun 2010; 5: 1349-1354

[44] Ali A, Cantrell CL, Bernier UR, Duke SO, Schneider JC, Agramonte NM, Khan I. Aedes aegypti (Diptera: Culicidae) biting deterrence: Structureactivity relationship of saturated and unsaturated fatty acids. J Med Entomol 2012; 49: 1370-1378

[45] Abbott WS. A method of computing the effectiveness of an insecticide. J Econ Entomol 1925; 18: 265-267

[46] Savin NE, Robertson JL, Russell RM. A critical evaluation of bioassay in insecticide research: Likelihood ratio tests of dose-mortality regression. Bull Entomol Soc Am 1977; 23: 257-266 